\title{
Modeling a possibility framework of a smart self-sustainable hybrid power generation system for a typical residential loading
}

\author{
Ifedayo Oladeji \\ Federal University of Technology Akure, Ondo State, Nigeria, oladeji.ifedayo@gmail.com, \\ orcid.org/0000-0002-9260-1107 \\ Aminat Oyinlola \\ Federal University of Technology Akure, Ondo State, Nigeria, wumgold@yahoo.com, \\ orcid.org/0000-0002-3393-5545 \\ Arrived: 09.04 .2018 Accepted: 10.06 .2018 Published: 30.06 .2018
}

\begin{abstract}
Generation of electricity using fossil fuels could be regarded as the greatest invention of mankind. However, with the depletion of this resource and also due to the effect of burning fossil fuels on the environment, it is imperative to find an alternative to generating electricity for local consumption using non-fossil fuel methods. In the bid to key into the global idea of power generation decarburization and also smart distribution system through the internet of things (IOT), this paper presents an active redundancy possibility framework for generating constant electricity from the motor-generator (M-G) and the battery-inverter (B-I) systems. The specifications of each component can be obtained from design models presented in this paper. The functionality of the system is achieved through the smart home distribution hub (SHDH). Each unit are modeled and simulated to obtain the transfer functions. The result of the residential loading is presented. The simulation results show that the system is achievable and also stable under circumstances which are being monitored and controlled by the smart hub. The framework presented in this paper has proved to be a viable and smart alternative source of electric energy for residential loading.
\end{abstract}

Keywords: Power electronics, Motor-GeneratorSet, Battery-Inverter Set, Smart control hub and Reliability,

Oladeji, I., Oyinlola, A. Modeling a possibility framework of a smart self-sustainable hybrid power generation system for a typical residential loading. Journal of Energy Systems 2018; 2(2): 70-83, DOI: 10.30521/jes.413691 


\section{INTRODUCTION}

The discovery of the generation of electric power has led to significant boost in global operations and economy. The level of development of a country is being measured by the total amount of electrical energy being generated [1]. While advanced countries like China, Japan, U.S.A are proud about generations around $356.6 \mathrm{GW}, 266.1 \mathrm{GW}$ and $979.6 \mathrm{GW}$ respectively [2] for developing countries, the generation level still averages around 3-7GW [3].

Despite the energy forecast of $28.41 \mathrm{GW}$ for Nigeria for year 2024 [4], the power generation is still as low as $5 \mathrm{GW}$ due to several constraints. Therefore, it is imperative for business and industrial units to make provisions for alternative electric power sources. In Nigeria today and well in most part of Africa, a generator set and/or an inverter system is mainly used as the alternative power source. The major challenges lie in the fluctuation of supply and constant increase in the price of fuel for the generator set and environmental concerns in terms of greenhouse gas (GHG) emission. Therefore, there is need for a sustainable and environmental friendly power supply system. A self-sustainable power generation system may be regarded as a standalone system having no interactions with any external system after excitation. In order words a self-sustainable system is modeled after a closed looped control system where there exists an interaction between the input and the output.

The inclusion of communication and control capabilities in a system for better operation, bi-directional interaction and efficient execution of commands describes smartness [5]. This research focuses on the generation of electric power for a typical Nigerian residential apartment using the combination of Batter-Inverter (B-I) and the Motor-Generator (M-G) set. Also the characteristic behaviors of individual unit of each set model as well as the overall model are presented.

\subsection{Smart Electrical Energy Network (SEEN)}

A smart network is an electrical network that can intelligently integrate all actions and processes of all discrete units (sources and loads) connected to it in order to efficiently deliver power to the loads [6], [7]. The conventional electrical network communication model is unidirectional and this has led to increased stress on the network, high level of unreliability and higher energy cost. In order to savage the condition of the network, a bi-directional operational model must be embraced. SEEN can be implemented both on large distribution systems in form of SMART grid which comprises of SCADA and home distribution systems in form of Home Energy Management System (HEMS).

Energy demand prediction for appliances in homes has a great influence in the functioning of a home energy management system. The functional framework of the control hub is given in Figure 1.

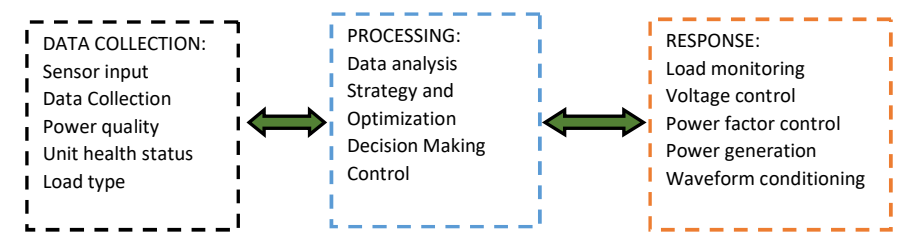

Figure 1. Smart Control Hub Framework 
This system is able to determine the best energy assignment plan and a good compromise between energy production and energy consumption. The Home Energy Management System is mainly composed of smart plugs, gateway, web server, database and a user device [8].

\subsection{Reliability of System}

Reliability is the probability of a system to perform its function adequately for the period of time intended under the prevailing operational conditions [9]. The efficient operation of a system may be guaranteed if there is a redundancy scheme in place. The smart self-sustainable model presented in this research implements the active redundancy concept. An active redundancy or parallel redundancy exists when the components of a system share the objective between them and the function is automatically absorbed by the other component if for any reason the other fails [10]. The block diagram model of the active redundancy including the supplementary unit blocks are shown in Figure 2 .

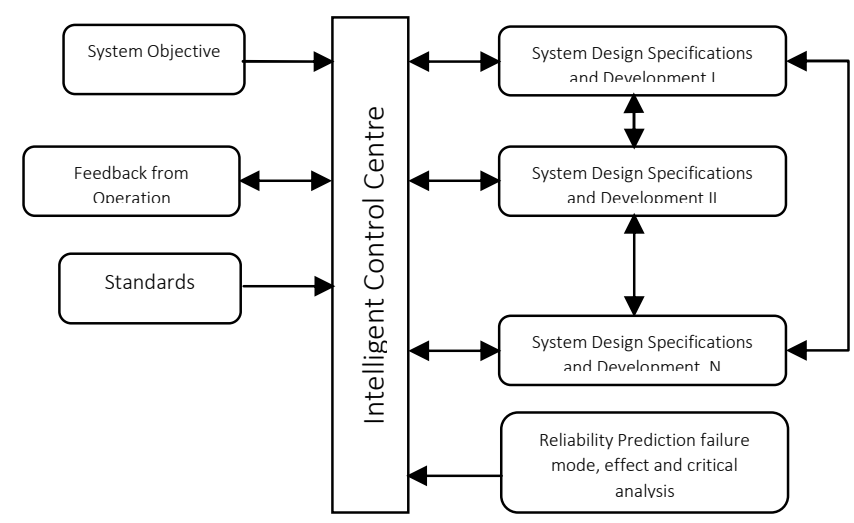

Figure 2. An Active Redundancy System Model

The smart hub is the heart of any modern active redundancy design. Its function includes amongst many other; to obtain necessary data from each unit design, provide analysis and proposal for overall system operational reliability improvement, identify potential problem areas and guide best load prioritization. The components of the intelligent control hub have been discussed in the previous section.

\subsection{Role of Power Electronics}

Power electronics can be explained as all devices, designs and systems related and concerned with the process of making the appropriate energy supply available to every different and distinct load types [11]. Power electronics systems are achieved through power semiconductor (power diodes, power transistors and thyristors) systematically arranged as switches to form converters. The characteristic role of a power electronics device is modeled in Figure 3. 


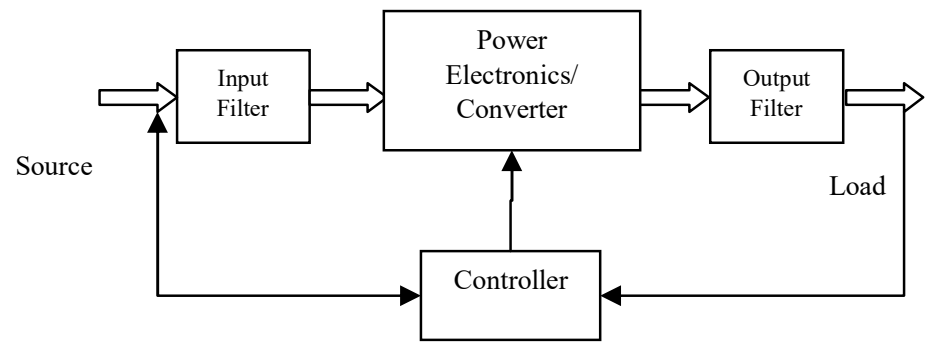

Figure 3.Design of a Power Electronic Device

Simply stated, power electronics is defined as the process of load-source energy demand matching. A residential load combination may consist of waveform dependent load (AC and DC), frequency and voltage dependent load. Power source conversion can occur in several forms of conversion; rectifiers from $\mathrm{AC}$ to $\mathrm{DC}$, inverters from $\mathrm{DC}$ to $\mathrm{AC}$, choppers from $\mathrm{DC}$ to $\mathrm{DC}$ and changers/cycloconverters which involves $\mathrm{AC}$ to $\mathrm{AC}$. The goal of power electronics is to provide electrical energy from one form to the other using small sized equipment, with high efficiency, high reliability and low cost [12]. Power Electronics systems are implemented using electronics devices which includes power diodes, power transistor (BJTs and MOSFET) and thyristors Power Electronics has found application also in renewable energy and storage systems namely; solar energy conversion technologies, wind turbines and fuel cells [13].

\section{MATHEMATICAL MODELLING}

The first step in any energy source design is to model the characteristics and behavior of the consumer load. Due to the dynamic nature of the residential loading, the following models are developed to evaluate the levels of consumption and hence to derive the load profile.

\subsection{Domestic Load Modeling}

Air conditioning, water heater and clothes washer/dryer constitute about $12 \%, 13 \%$ and $5 \%$ of the total domestic energy consumption respectively [14]. Taken that the power consumption $P_{C_{-} H}$ water heater depends on the characteristics of the water heater and the efficiency of the heater, it may be expressed as Eq.[1];

$$
P_{C_{-} H}=P_{R_{-} H} \times G_{H} \times \eta_{H}
$$

where $P_{R_{-} H}$ is the power rating of the water heater, $G_{H}$ is the characteristics of the heater and $\eta_{H}$ is the efficiency of the heater. $G_{H}$ is a function of the water heater hot water temperature set point in ${ }^{\circ} \mathrm{C}$, outlet water temperature in ${ }^{\circ} \mathrm{C}$ and lower tolerance of the hot water temperature in ${ }^{\circ} \mathrm{C}$.

Also, the power consumption $P_{C_{-} D}$ of clothes dryer in each operation interval can be expressed as in the following.

$$
P_{C_{-} D}=\left(k \times P_{R_{-} C} \times G_{D}\right)+\left(P_{R_{-} M} \times G_{D}\right)
$$


where $k$ is the constant of washing/drying level, $P_{R_{-} C}$ and $P_{R_{-} M}$ are the power rating of the coil and motor components respectively. $G_{D}$ is a function of the accumulated time of usage and the required duration of usage both in minutes?

Furthermore, the power consumption $P_{C_{-} A}$ of the AC cooling unit can be expressed by Eq.[3];

$$
P_{C_{-} A}=P_{R_{-} A} \times G_{A}
$$

where $P_{R_{-} A}$ is the power rating of the $\mathrm{AC}$ unit and $G_{A}$ is the characteristic property of the cooling unit which depends on the operating room temperature, thermostat set point and the cooling unit set temperature deviation tolerance level all in ${ }^{\circ} \mathrm{C}$.

\subsection{Power Electronics Converter Model}

The function of Power Electronics devices in the actualization of the proposed sustainable electric power supply is crucial. As highlighted in section I-C, the different types P.E converters discussed are modeled below. Given a resistor, inductor and capacitor of R, L and C values respectively, Eqs.[4-5] presents the normalized model for the boost converter voltage and current.

$$
\begin{gathered}
\frac{d i}{d t_{n}}=-\left(1-I_{a v}\right) v+1 \\
\frac{d v}{d t_{n}}=\left(1-I_{a v}\right) i-\frac{v}{P}
\end{gathered}
$$

Also the normalized model of the buck converter for the D.C power supply to the DC is presented in Eqs.[6-7].

$$
\begin{gathered}
\frac{d i}{d t_{n}}=-v+I_{a v} \\
\frac{d v}{d t_{n}}=i-\frac{v}{P} \\
t_{n}=\frac{t}{\sqrt{L C}} \\
p=\sqrt{\frac{L}{C}}
\end{gathered}
$$


Where $i$ and $v$ are the normalized inductor current and the normalized output voltage respectively, $I_{a v}$ is the average control input. $t_{n}$ is the normalized time and $P$ is the inverse of the quality factor of the current [15].

\section{MODEL RESULT AND DISCUSSION}

This section presents the result of load evaluation and the proposed model of hybrid self-sustainable power supply unit. Also, the Simulink model and result of the M-G and B-I sets are presented.

\subsection{Load Evaluation}

This discussion section presents the result for evaluation of the consumption of electric energy in $\mathrm{kW}$ for a particular residential apartment. Table I shows the common load type for a typical residential apartment with their corresponding diversity factors (D.F).

Table 1. Common Residential Load and Rating

\begin{tabular}{lllll}
\hline S/N & Load Type & Approximate KW & Proposed D.F & Total KW \\
\hline 1 & Lighting & 1.2 & 0.7 & 0.84 \\
2 & Small AC Load & 1.5 & 0.7 & 1.05 \\
3 & Small DC Load & 1 & 0.6 & 0.6 \\
4 & Pumps & 1.5 & 0.6 & 0.9 \\
5 & Laundry & 3 & 0.65 & 1.95 \\
6 & Kitchen load & 4.2 & 0.75 & 3.15 \\
7 & HVAC & 4.3 & 0.8 & 3.44 \\
8 & Domestic Utilities & 1.8 & 0.7 & 1.26 \\
& Total & 18.5 & & 13.19 \\
\hline
\end{tabular}

The diversity factor is a constant that is dependent on the frequency and duration of usage of each load type. High D.F implies that the load is a critical load that is seldom unused while an apparently low D.F implies the load types that is timely operated.

\subsection{Proposed Model}

This paper presents a framework for constant generation of electric power using a combination of B-I and M-G sets as shown in Figure 4. The input to the system could be a supply from a PV array or rectified AC power supply. The model represents an energy conversion system; mechanical to electrical energy with a coupler to reduce the conversion loss. At each node (DC and AC), sensors are installed for measurement, protection and communication applications. The measured parameters at the nodes may include frequency, voltage, current and power. Also, the harmonics generated by the Power Electronics converters are to be monitored and filtered out at the immediate nodes. 


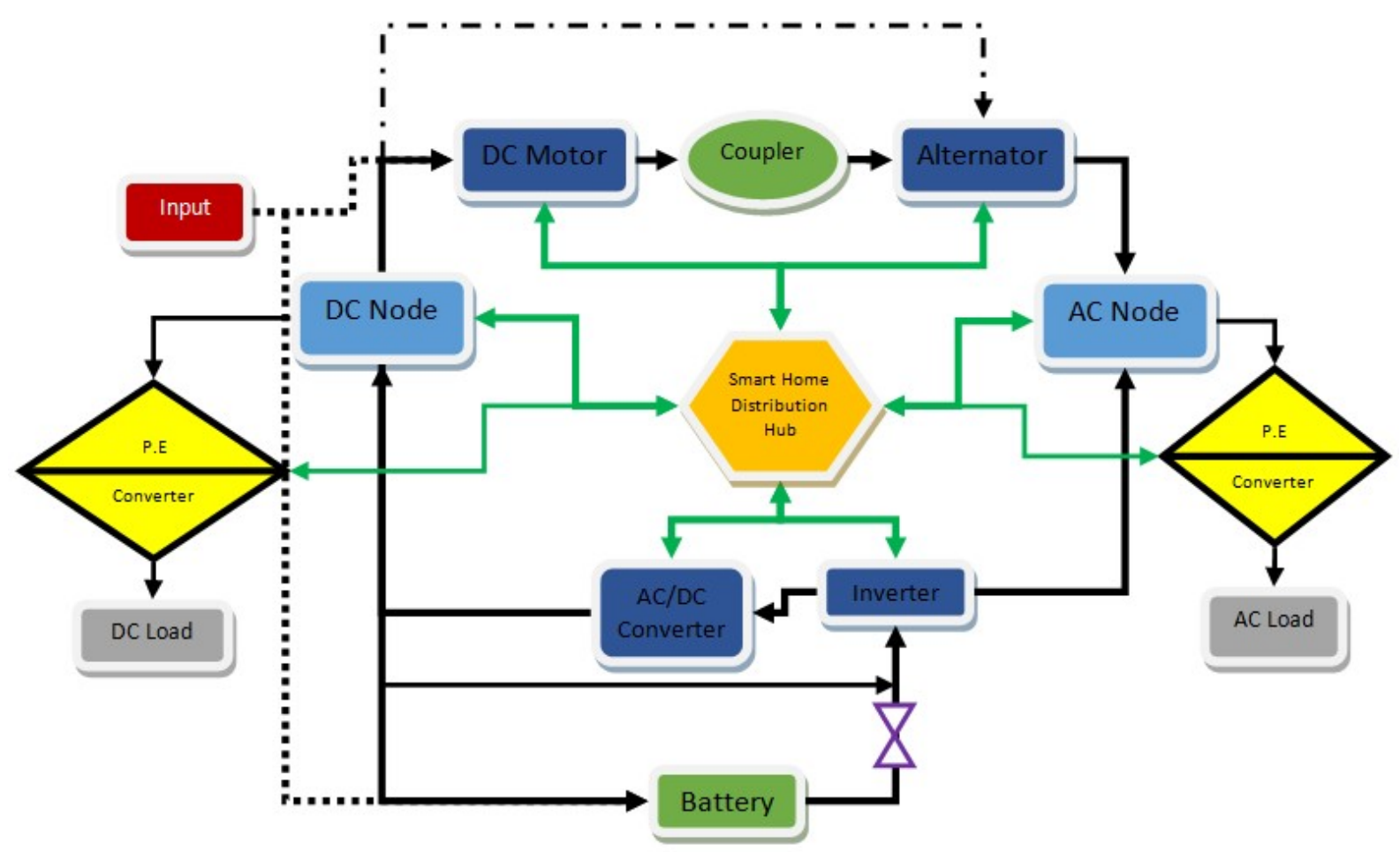

Figure 4. Proposed Framework for Constant Power Generation

The principal unit of the model for coordination and control is the Smart Home Distribution Hub (SHDH). The unit consists of communication, monitoring and control protocols for overall operation control between the two individual sets (B-I and M-G) for optimum operational efficiency. The field windings of the alternators are supplied by the DC input for field excitation. Each operational unit is equipped with appropriate sensor to enhance communication with the SHDH. The SHDH also consist of electrical switches for isolation of one unit from the other in case of malfunction or any other reasons so as to ensure constant supply to the consumer load. Coordination through the smart hub is achieved through; the smart energy meter for data collection and management, load pattern analysis, intelligent load shedding, energy saving and home area network (wireless or ZigBee) for IOT enablement, communication and control.

\subsection{Motor and Generator Set (M-G Set)}

The M-G set is an arrangement of a D.C shunt motor coupled with an A.C alternator as shown in Figure 5 .

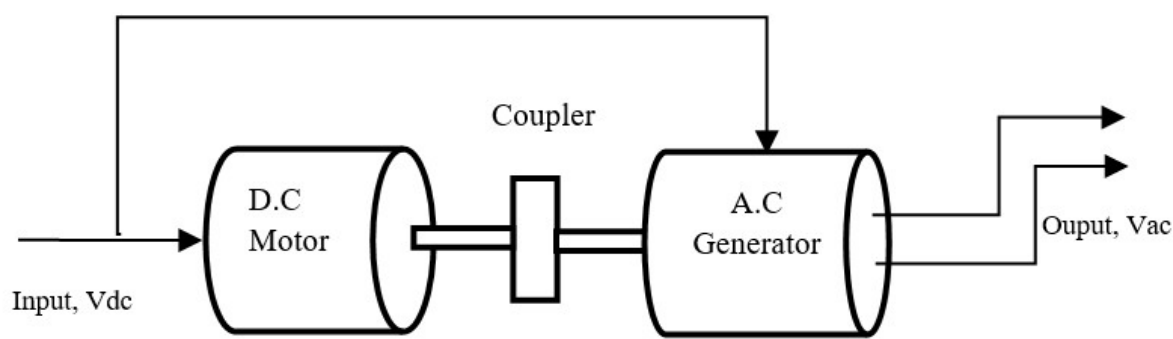

Figure 5. The M-G Set Model 
The choice of the motor and generator used for the M-G set is determined by the ratings and specifications obtained through design to meet with the individual load demand. An alternator rotor needs to be driven by an external force (prime mover) for electricity to be generated. This mechanical force is provided by the rotational output from the D.C motor.The Matlab Simulink model of the D.C motor proposed in this research is given in Figure 7.

The transfer function representation of the shunt type D.C motor for the M-G set is shown in Figure 6. The input is electrical energy in the form of direct current $\left(i_{a}\right)$ while the output is mechanical rotation in form of angular rotation (w). The values of the D.C motor constants which includes the inductance (L), the resistance(R), the motor torque constant $\left(K_{t}\right)$, the back EMF constant $\left(K_{b}\right)$ and the viscous friction $(b)$, are all carefully chosen in order to obtain the best response and interaction with the alternator in terms of stability.

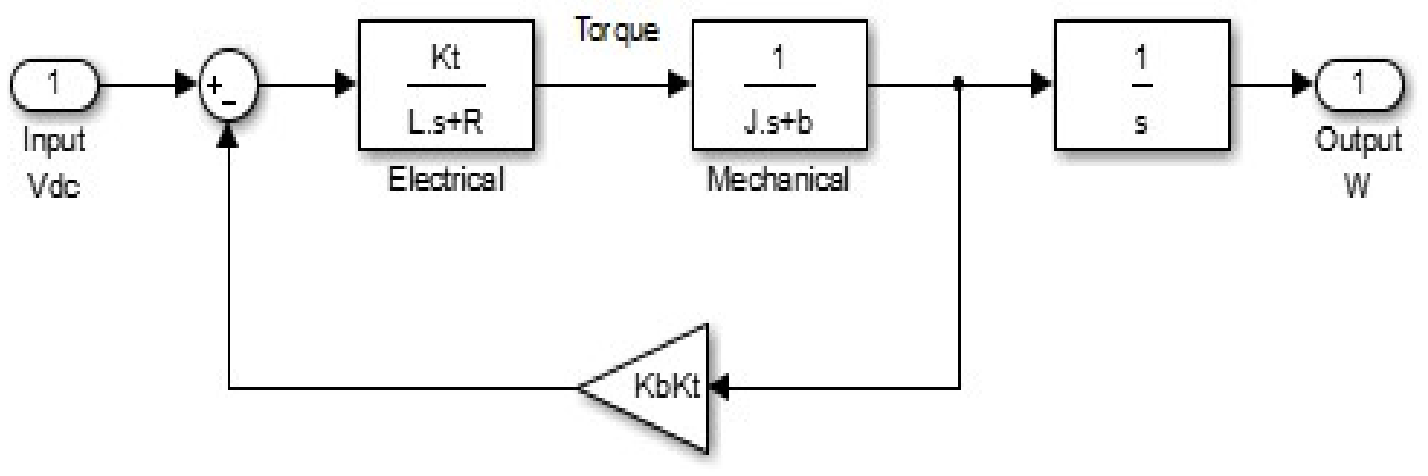

Bad Emf

Figure 6. Transfer Function Model of a DC Motor

The Simulink model of the block diagram in Figure 6 is shown in Figure 7. It consists of devices for measurement and control of the armature current and the angular speed.

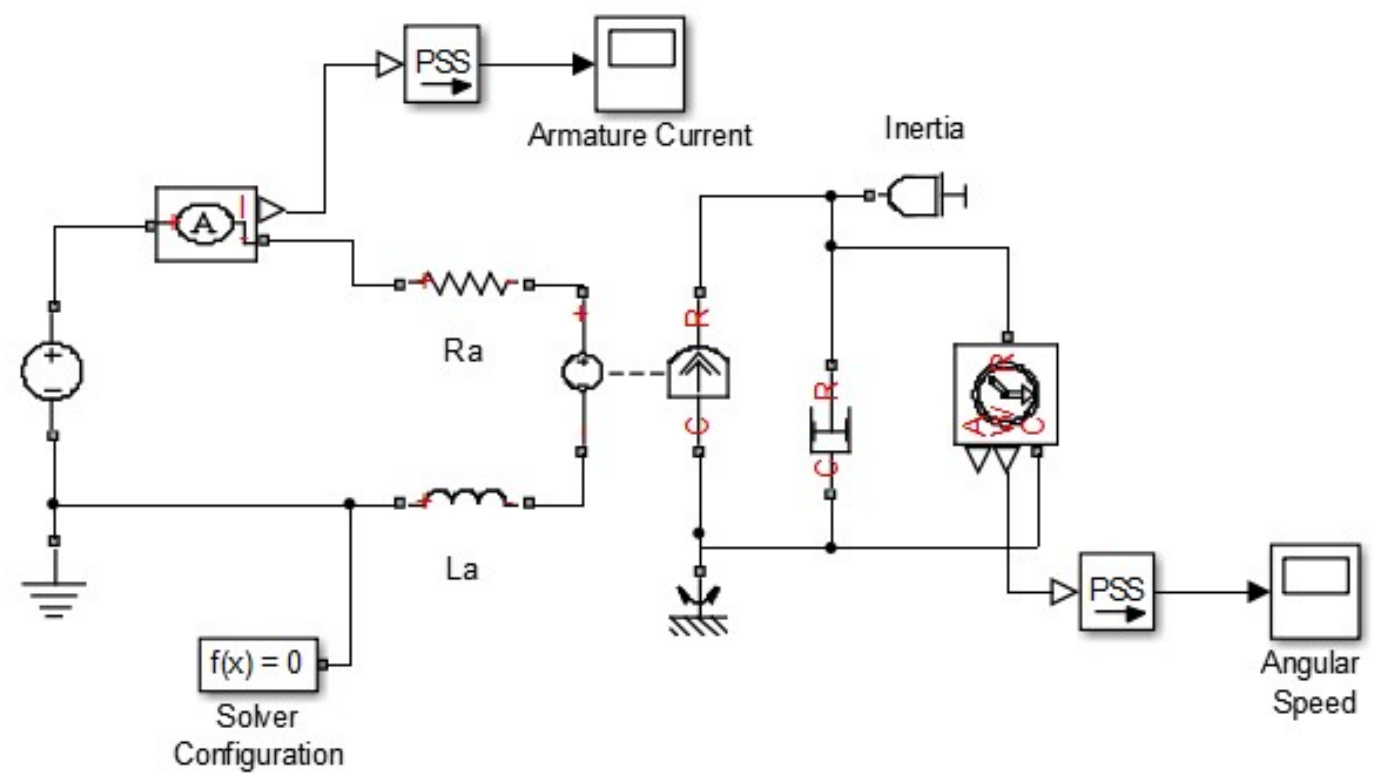

Figure 7. DC motor Modelling on Simulink 
The Simulink model of the alternator for the M-G set is shown in Figure 8. The input from the prime mover is attached to the input reference where the speed is measured and controlled.

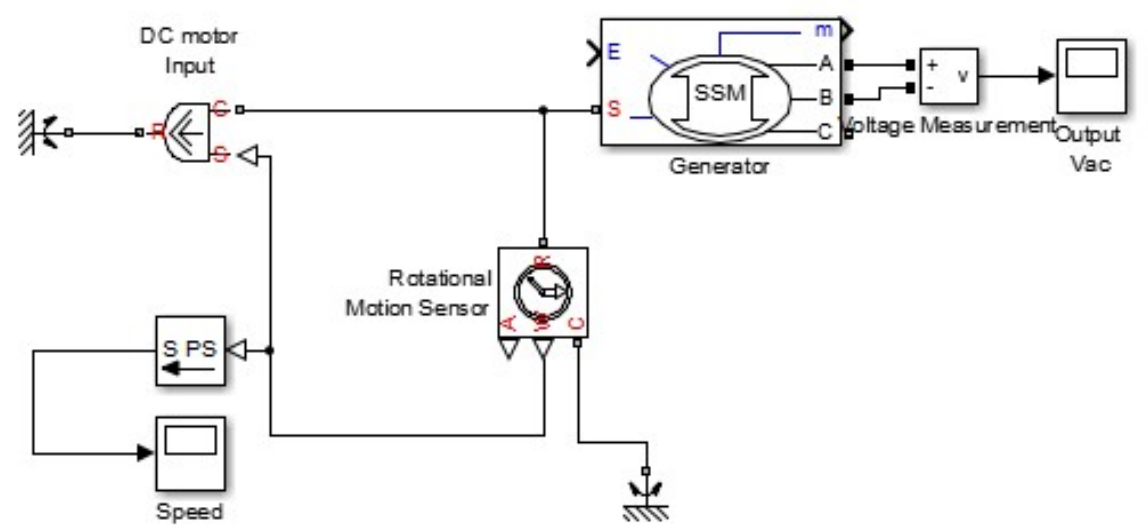

Figure 8. Generator Modelling on Simulink

The behavior of the alternator is characterized by Eqs.[10-11].

$$
\begin{gathered}
\Delta \omega(t)=\frac{1}{2 H}=\int_{0}^{t}\left(T_{m}-T_{e}\right) \delta t-K_{d} \Delta \omega(t) \\
\omega(t)=\Delta \omega(t)+\omega_{0}
\end{gathered}
$$

where $\Delta \omega$ is the speed variation, $H$ is the inertia constant, $T_{m}$ is the mechanical torque, $T_{e}$ is the electromagnetic torque, $K_{d}$ is the damping factor, $\omega(t)$ is the mechanical speed and $\omega_{0}$ is the speed of rotation [16].

The signal flow diagram of the M-G set is shown in Figure 9. The system gains are numbered G_1 to G_6. 


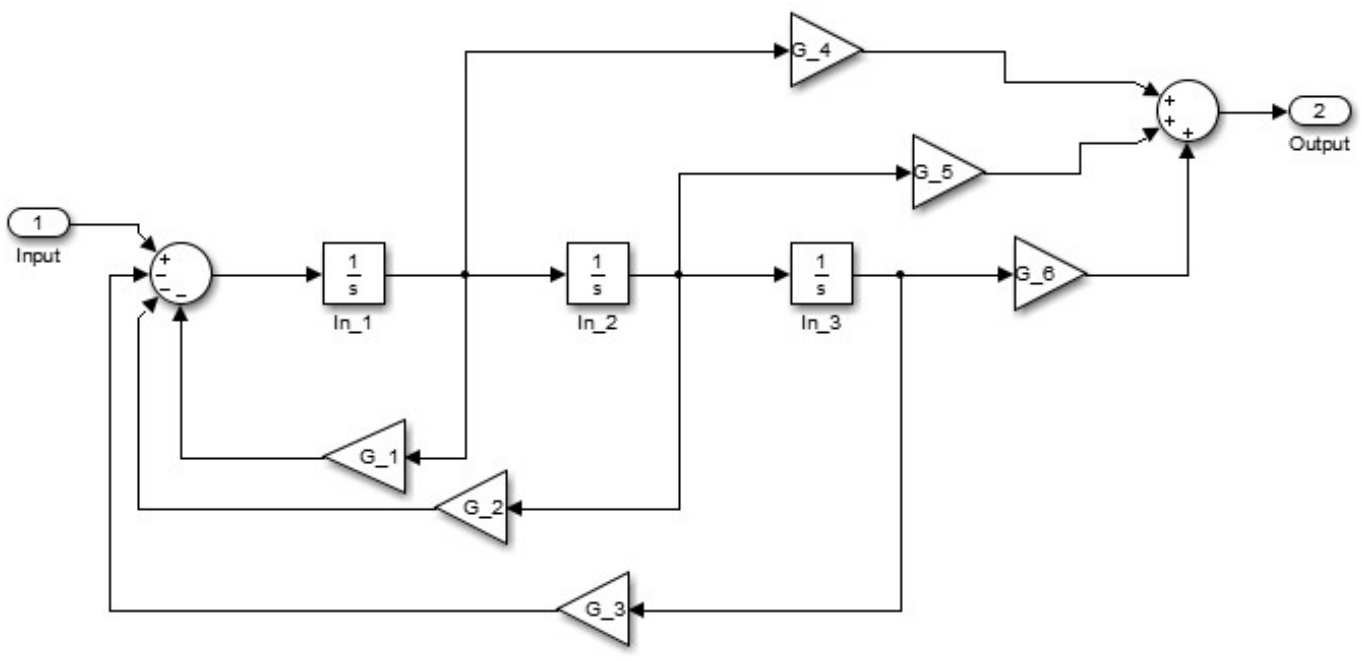

Figure 9.Motor Generator unit Simulink model

\subsection{The Battery and Inverter Set (B-I)}

The B-I set may be seen as the redundancy backup for peak load periods. The battery is charged through the initial D.C input and supplies the A.C inverter with the input stored D.C energy. A control switch is inserted after the battery to isolate it after few seconds of attaining operational stability through the help of a capacitive buffer system. The transfer function diagram model of the single phase voltage source inverter (VSI) is shown in Figure 10.

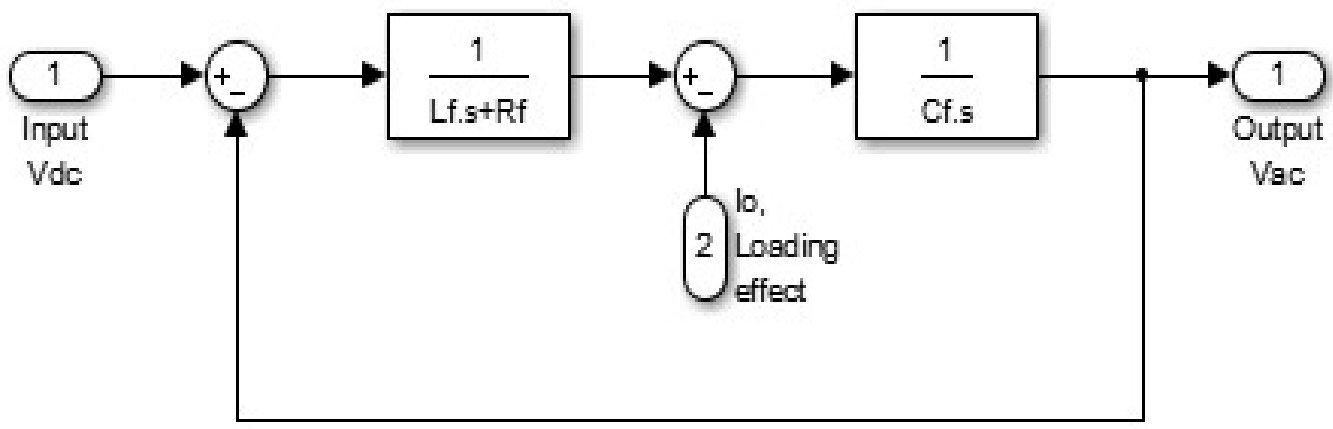

Figure 10. Transfer Function Model of a single phase VS inverter

As with the DC motor, the performance of the VSI is dependent on the specific equivalent parameters of the model which includes the inductance (Lf), resistance (Rf) and the capacitance (Cf). These parameters are determined from design specifications and also a loading effect which is the control signal for the control hub as a feedback to ensure optimum performance is included.

Figure 11 presents the Simulink model of the single phase VS inverter. T1 to T4 are Metal Oxide Silicon Field Effect Transistors (MOSFETs). The switching operating of T1-T4 with the introduction of Pulse Width Modulation (PWM) generates pure sine wave A.C power to power domestic loads. 


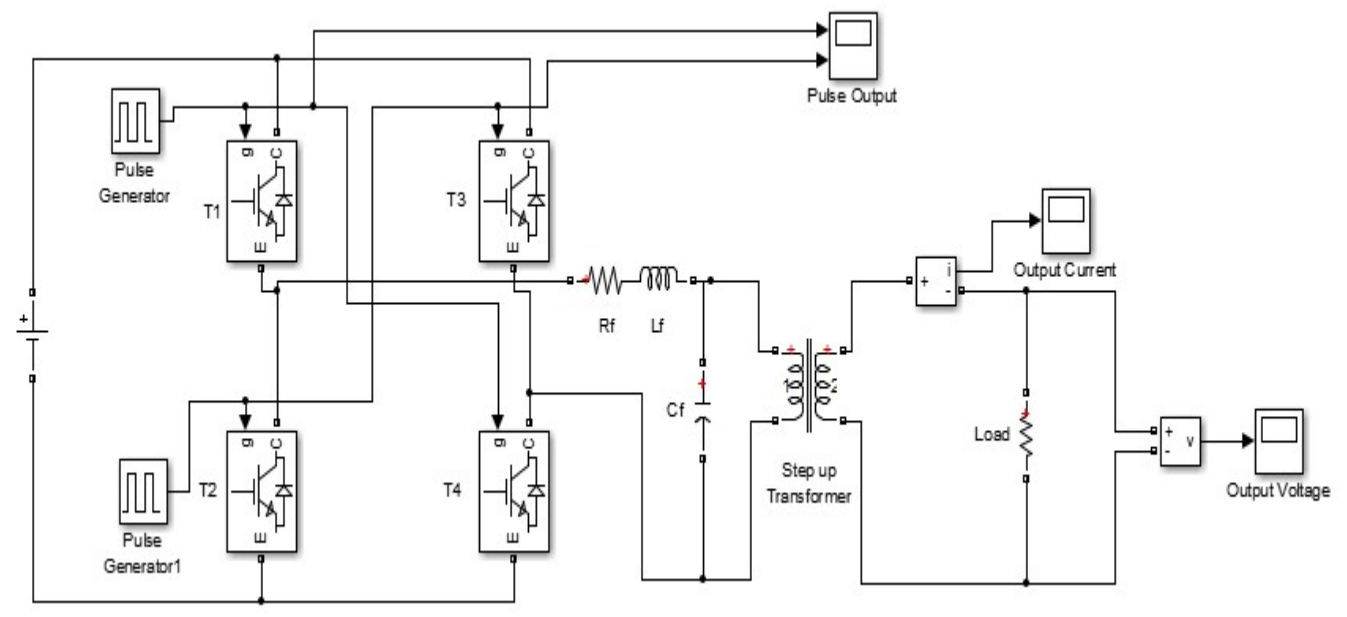

Figure 11. Single phase Inverter modelling on Simulink

The control parameters of the VS inverter are the output voltage $\left(V_{o}\right)$, output current $I_{o}$ and the pulse output $\left(G_{o}\right)$.

Figure 12 shows the behavior of the prime mover (DC motor) when it is being loaded. Characteristically, the armature current is very high at start up but decays exponentially until is settles around a steady state value of $0.1 \mathrm{~A}$ scaled.

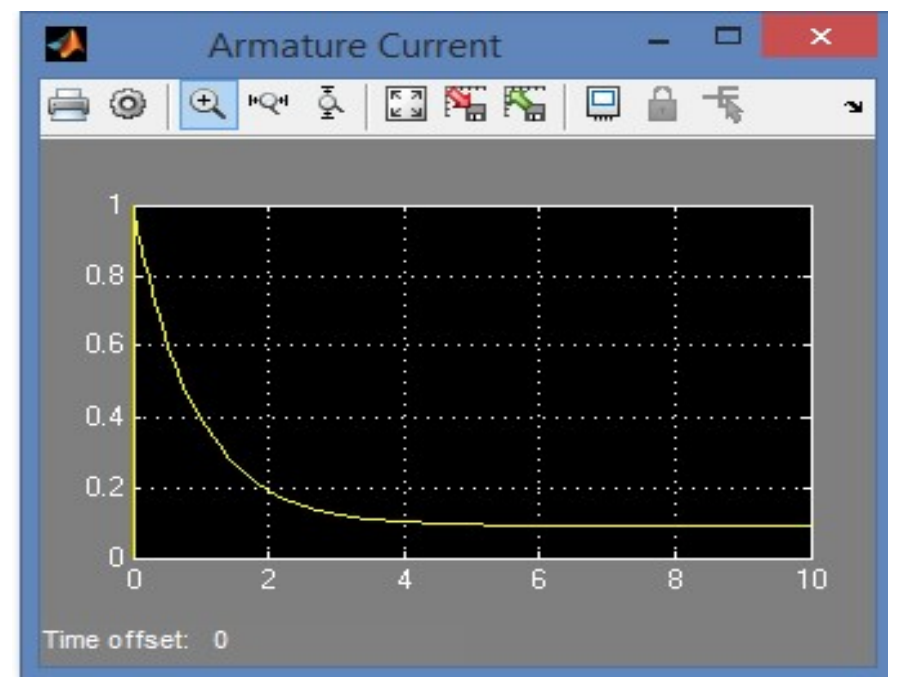

Figure 12. DC Motor Armature Current

The plot of the DC motor angular speed against time is shown in Figure 13. At start up, the speed is zero but also rises exponentially in less than 3 seconds to attain stability around $83 \mathrm{rad} / \mathrm{s}$. 


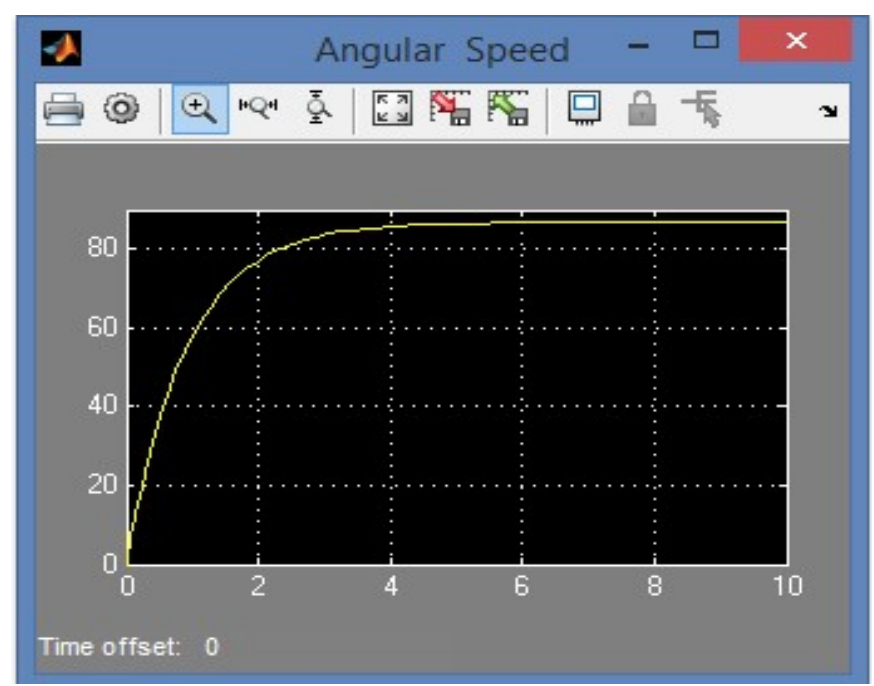

Figure 13. DC Motor Rotor Angular Speed

The output voltage and current from the combined M-G and B-I set are shown in Figures 14 and 15

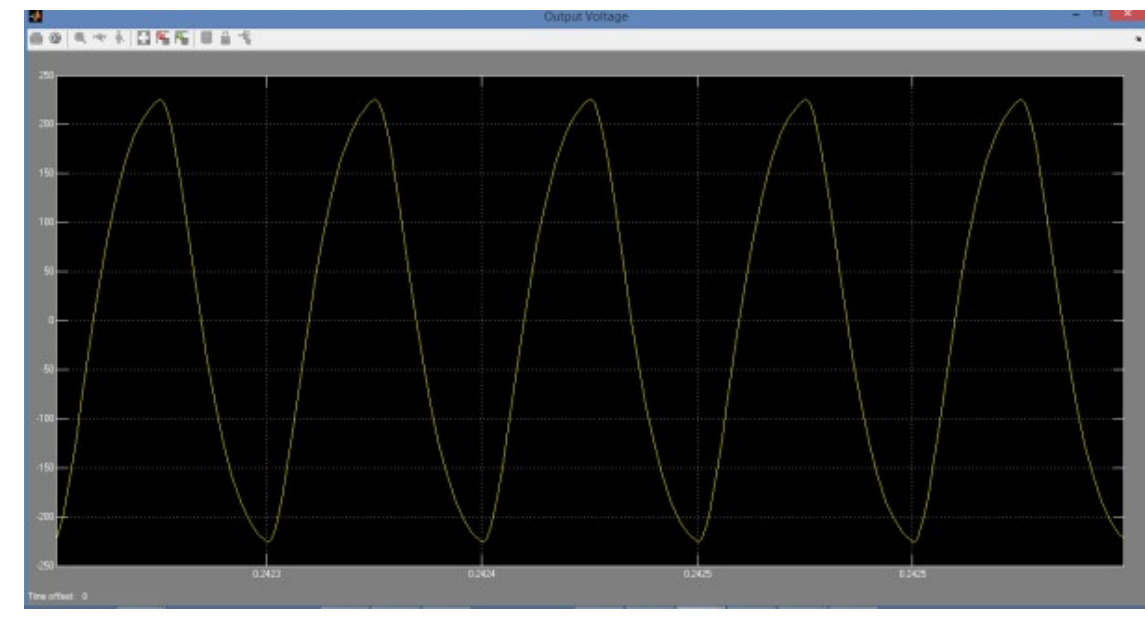

Figure 14. System Output Voltage

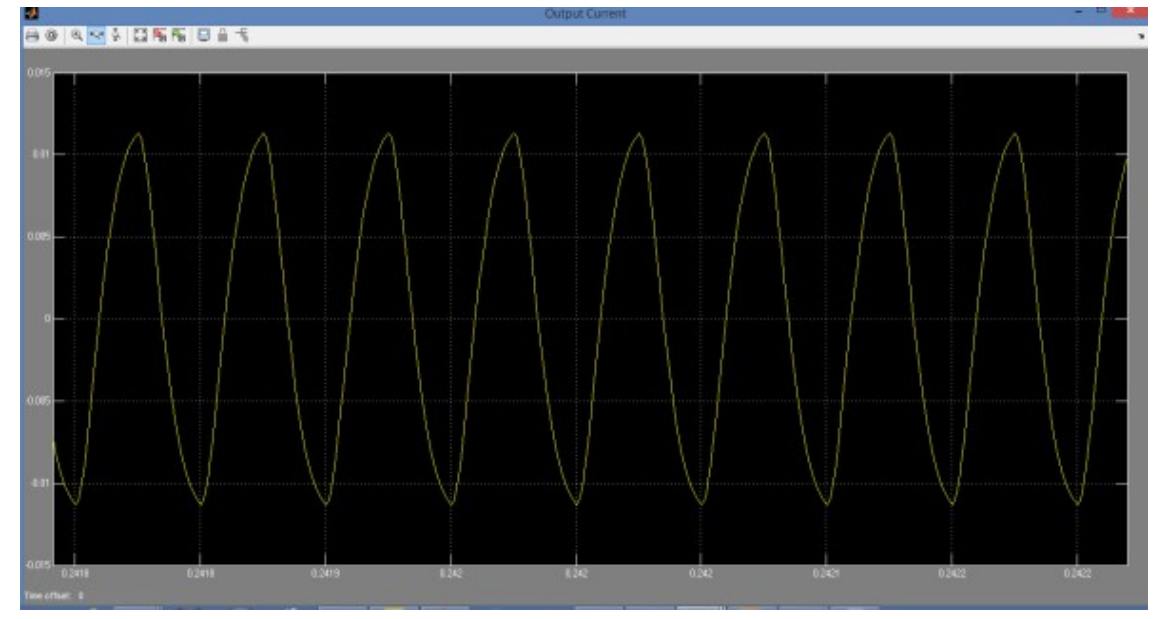

Figure 15. System Output Current 
While the value of the output current waveform and magnitude depends on the system loading, the voltage waveform is absolute sinusoidal with peak at $230 \mathrm{~V}$.

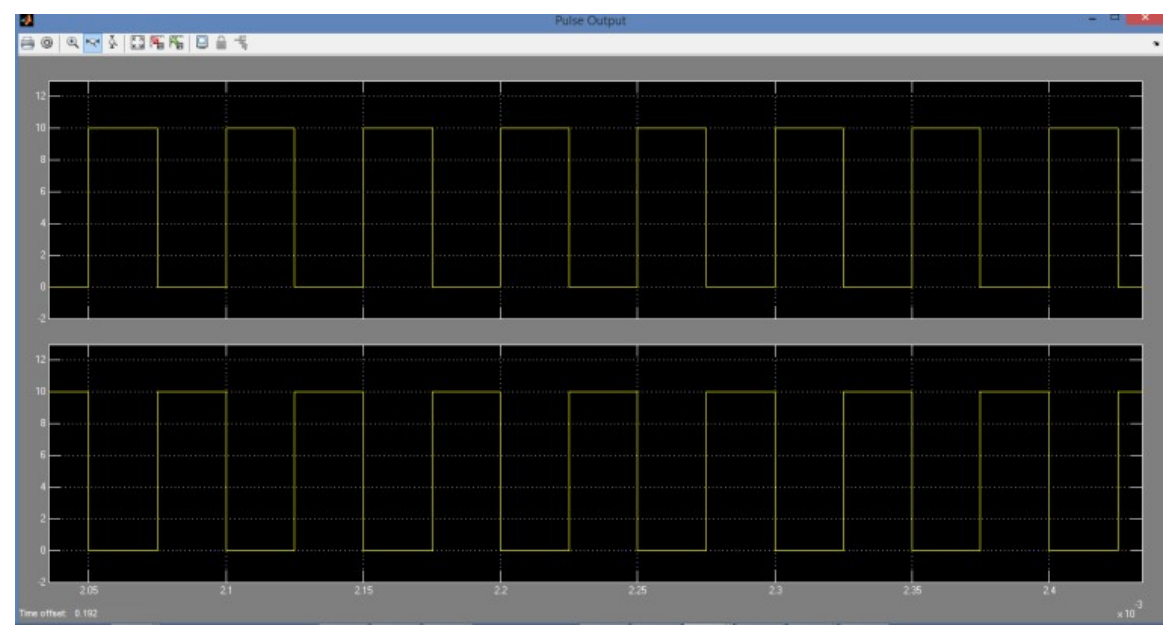

Figure 16. System Inverter Triggering Output Gate Pulse

Figure 16 above shows the pulse output of the VS B-I set for transistors T1T4 and T2T3.

\section{CONCLUSION}

In the light of growing energy demand and the shift of focus from fossil energy to renewable energy sources, this paper has presented a workable and achievable source of constant generation of electricity. The model presented is self-sufficient and sustainable with the incorporation of the smart home distribution system (SHDH) which monitors and controls the processes and functionalities of all the units put together. The model can be achieved using locally available electronics components and mechanical materials. This would greatly impact the cost of generation of electric power. Lastly, this framework could be considered as an alternative to or as a form of distributed generation (DG) of electricity.

\section{REFERENCES}

[1] Adeyemi, A. O., Ayomide, A. Electricity Consumption and Economic Growth in Nigeria. Journal of Business Management and Applied Economics, 2013. 1-14.

[2] Japan Electric Power Information Center. Overseas Electric Power Industry Statistics. Japan: Overseas Electric ower Industry Statistics, 2005.

[3] Transmission Company of Nigeria, Nigeria Electricity System Operator-Electricity Power Monitoring and Control. Retrieved 12 09, 2017, from Nigeria Electricity System Operator: https://www.nsong.org

[4] Melodi, A. O., Momoh, J. A.,Adeyanju, M. O. Probabilistic Long Term Load Forecast for Nigerian Bulk Power Transmission System Expansion. IEEEXplore Digital Library, 2016, 301-305.

[5] Hyunjeong, L, Wan-Ki, P., Il-Woo, L. A Home Energy Management System for Energy-Efficient Smart Homes. International Conference on Computational Science and Conputational Intelligence, 2014(pp. 142147). South Korea: IEEE.

[6] Buchholz, B. M., Styczynski, Z. Smart Grids-Fundamentals and Technologies in Electricity Network, 2014. New York: Springer.

[7] Vaibhavi, S. Y.. Design of Smart Home Energy Management System. International Journal of Innovative Research in Computer and Communication Engineering , 2015, 1851-1857.

[8] Ryszard, S.Benysek, G. Power Electronics in Smart Electrical Networks. London: Springer, 2008.

[9] Bauer,E. X., Zhang, Kimber, D. A.Practical System Reliability. New Jersey: Wiley IEEE Press, 2009

[10] Billinton, R.,Allan, R. N.Evaluation Evaluation of Engineering Systems-Concepts and Techniques. New York: Springer Science Business Media, 1992.

[11] Krein, P. T.Elements of Power Electronics. New York: Oxford University Press, 1998. 
[12] Robert, E. W., Maksimovic, D.Fundamentals of Power Electronics. New York: Kluver Academic Publishers, 2004.

[13] Yuriy, R., Sergey, R., Evgeny, C., Voronin, P. Power Electronics Basics-Operating Principles, Design, Formulas and Applications. London: CRC Press, 2016.

[14] The National Academies of Sciences Engineering Medicine. How We Use Energy. Retrieved December 11, 2017, from What You Need To Know About Energy: http://needtoknow.nas.edu, 2017.

[15] Sira-Ramirez, H.,Silva-Ortigoza, R. Control Design Techniques in Power Electronics Devices. New Jersey: Springer, 2006.

[16] Saadat, H. Power System Analysis. New York: McGraw-Hill, 1999. 